\title{
Interações dinâmicas entre os materiais do leito de um canal secundário com o canal principal no trecho multicanal do Alto Rio Paraná, Brasil.
}

\author{
Paulo César Rocha ${ }^{1}$ e Edvard Elias de Souza Filho ${ }^{2}$ \\ 1 Universidade Federal de Mato Grosso do Sul CEUL/DCH, GEMA/UEM. Av. Ranulpho M. Leal, 3484, V. \\ Industrial. Três Lagoas-MS. cep 79610-100. e-mail pcrocha@ceul.ufms.br \\ 2 Universidade Estadual de Maringá DGE/GEMA. Maringá-PR
}

\begin{abstract}
Resumo
Neste trabalho foram avaliadas as características dos sedimentos de fundo de um canal secundário - o canal Cortado - e interpretadas de acordo com a dinâmica dos canais principais do sistema multicanal do rio Paraná. Os dados hidrodinâmicos e dos materias do leito foram tomados em seção transversal, durante um ciclo hidrodinâmico. Os resultados mostraram predominância de areias médias com bom selecionamento durante todas as amostragens, porém, as areias finas e grossas mostraram com freqüência inversa ao que se esperava pelos parâmetros da geometria hidráulica. Esse fato pode ser explicado porque, durante a cheia, há passagem de formas de leito provenientes do canal principal do rio Paraná, com predominância de areias médias e areias finas. Tais formas sobrepõe-se aos sedimentos mais grosseiros do leito, aumentando sua freqüência, e, durante o período de abaixamento das águas, os termos mais finos podem ser paulatinamente removidos, levando à concentração dos grãos de maior diâmetro.
\end{abstract}

Palavras-chave: Material do Leito; Hidrodinâmica; Rio Paraná.

\begin{abstract}
In this work were available the sedimentological characteristics of Cortado's channel bed load, a secondary channel of the multichannel Parana river, and correlated with its dynamic, at Porto Rico town area. The load material and hydrodynamic datas were obtained by cross-sections in these channels, over the hydrological cycle. The result shows that the mean sands prevailed with very good selection during the sampling, and the frequency of coarse sands and fine sands has been inverted relation with the flow energy and hydraulic geometry parameters. This case can be explained because during the high flow, had influence from the highly mobiles bed-forms in the main sandy-bed channels, which dominate mean and fine sand. This forms moves over the coarse surface of the channel bed in the high flow elevating its frequency. During the lower flow, the fine grains are slowly removed promoting then major coarse grain concentration on the bed.

Keywords: Bed Material; Hydrodynamic; Parana River
\end{abstract}

\section{Introdução}

O escoamento nos canais fluviais apresenta diversas características dinâmicas que se tornam responsáveis pelas qualidades atribuídas aos processos fluviais. A dinâmica do escoamento, no que se refere à perspectiva geomorfológica, ganha significância na atuação exercida pela água sobre os sedimentos do leito fluvial, no transporte dos sedimentos, nos mecanismos deposicionais e na esculturação da topografia do leito (Christofoletti, 1981).

A morfologia de um sistema fluvial reflete uma história denudacional. Segundo Petts \& Foster (1990), os rios podem ser vistos como um sistema aberto, em termos de entrada (input) e saída (output) de massa e energia, e como sistemas de processoresposta, mantendo 3 características: 1- sua operação é controlada pela magnitude e freqüência de inputs; 2- mudanças progressivas na morfologia e operação do sistema podem ocorrer se mudanças nos inputs ou degradação interna do sistema ocorrerem; 3- auto-regulação ou trocas negativas (feedback) podem ocorrer criando um novo estado de equilíbrio entre as formas e os processos.

Considerando a variabilidade dos fluxos, os eventos de magnitude moderada e de ocorrência relativamente freqüente controlam a forma do canal. Nessa categoria, os débitos de margens plenas (débitos com recorrência entre 1 a 3 anos) surgem como os de maior poder efetivo na esculturação do modelado do canal, pois as ondas 
de fluxo escoam com uma ação morfogenética ativa sobre as margens e fundo do leito, possuindo competência suficiente para movimentar o material detrítico (Wolman \& Miller, 1960; 1974; em Christofoletti, 1981). A geometria hidráulica de canais aluviais é, em geral, ajustada a eventos de escoamento de menor intensidade, tendo intervalo de recorrência de uns poucos anos somente nas regiões úmidas, e de 30-100 anos nas regiões mais áridas. No entanto, os impactos morfológicos dos eventos (descargas) são parcialmente um problema tanto da magnitude do tempo de intervalo entre os picos, quanto da magnitude dos picos para qualquer forma de relevo. Obviamente, tanto a água como o transporte de sedimentos são muito importante para o entendimento da morfologia do canal (Chorley et al., 1985).

Torna-se de grande importância o entendimento funcional dos sistemas fluviais, dos aspectos hidrodinâmicos e das variáveis que mantém o equilíbrio dinâmico, como as que se relacionam com o trabalho que o rio executa em cada trecho, principalmente em ambientes tropicais, ainda pouco estudados.

Neste sentido, a parte média do alto rio Paraná vem sendo estudada por uma equipe multidisciplinar desde o final da década de 1980 [oitenta]. Neste período, os estudos sobre a dinâmica fluvial estiveram concentrados nos canais principais, e o trabalho pioneiro em canais associados e secundários foi levado a termo por Rocha \& Souza Filho (1996), que estudaram a erosão marginal no rio Baía, canal Curutuba, rio Ivinheima, e no canal Cortado, no período entre 1993 e 1995, e posteriormente Rocha et al. (1999), avaliando os dados de erosão marginal numa abordagem comparativa entre os canais secundários e principais do sistema.

Neste trabalho, os objetivos foram avaliar as características granulométricas dos sedimentos de fundo de um canal secundário, o canal Cortado, em uma seção transversal ao longo de um ciclo hidrodinâmico e observar as interações com o transporte de fundo dos canais principais do trecho multicanal do Alto Rio Paraná, na região de Porto Rico-PR

\section{2.Área de Estudos}

O rio Paraná, grande controlador desse sistema de inundação, apresenta canal único e com talvegue principal situado junto à margem esquerda em Porto São José-PR (seção 1). Nesta seção atinge velocidades próximas a $1,5 \mathrm{~m} / \mathrm{s}$. Para jusante, encontra-se dividido por extensos arquipélagos (trecho multicanal) até as proximidades da segunda foz do rio Ivinheima, onde apresenta outro trecho de canal único. Ao longo das ilhas possui dois canais principais, dos quais o esquerdo é sempre maior e mais profundo. Inúmeros canais secundários separam as inúmeras ilhas, permitindo uma configuração em planta do padrão entrelaçado (Souza Filho \& Stevaux, $1997-$ a) (figura 1). Atualmente, a vazão média na estação de Porto São José-PR é de $9.729 \mathrm{~m} 3 / \mathrm{s}$ (período 1983/2001), e tem sido elevada desde o início da década de 1970 .

O canal Cortado (seção 2) está situado junto à margem esquerda do rio, a pouco mais de 10 quilômetros a jusante da cidade de Porto Rico. ues

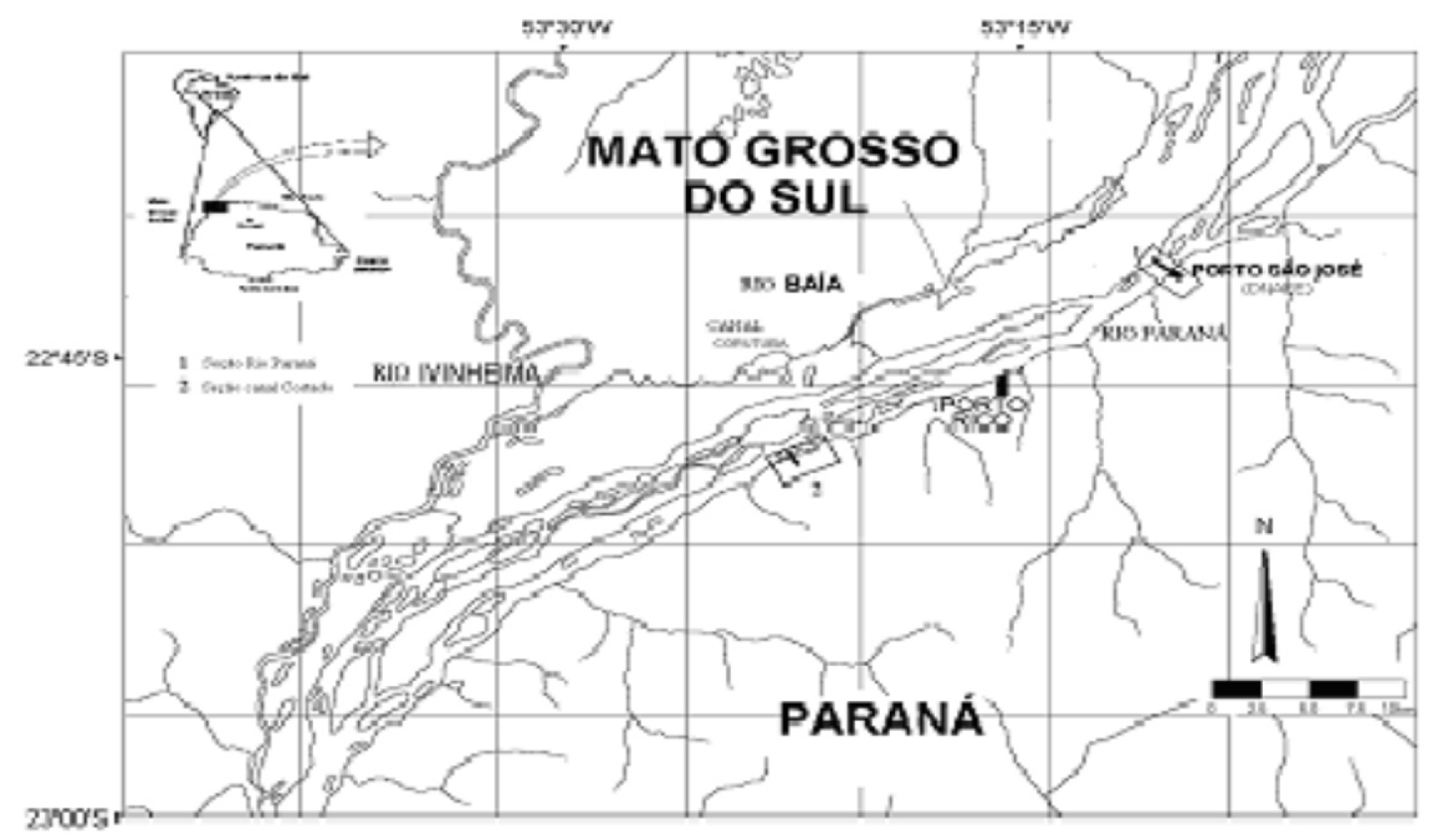

Figura 1. Localização da área de estudo no Alto Rio Paraná: 1- seção hidrológica de Porto São José; 2- seção canal Cortado. 
Possui cerca de seis quilômetros de extensão, 50 metros de largura, e pouco mais de 1 metro de profundidade média. Ao longo das últimas cinco décadas passou por períodos de assoreamento (1953-1965), re-entalhe de baixa intensidade (1966-1983) e aprofundamento (1983-1989), acompanhando a evolução de área do conjunto Carioca, descrita por Fernandez \& Souza Filho (1995). Atualmente, encontra-se em processo de assoreamento. Apesar de pertencer ao conjunto de canais entrelaçados, apresenta diques marginais bem desenvolvidos, alta estabilidade marginal, com recuo anual da margem da ordem de 3 a $4 \mathrm{~cm} \mathrm{e}$ velocidades médias entre 0,15 e $0,56 \mathrm{~m} / \mathrm{s}$ (Rocha \& Souza Filho, 1996). Nele, ocorre um processo de

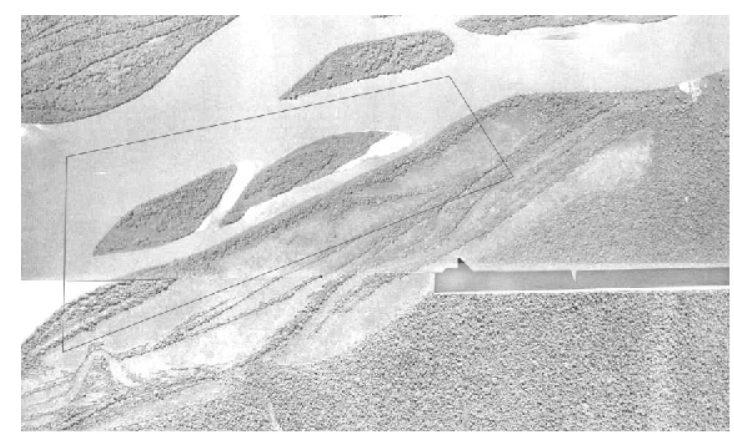

1953

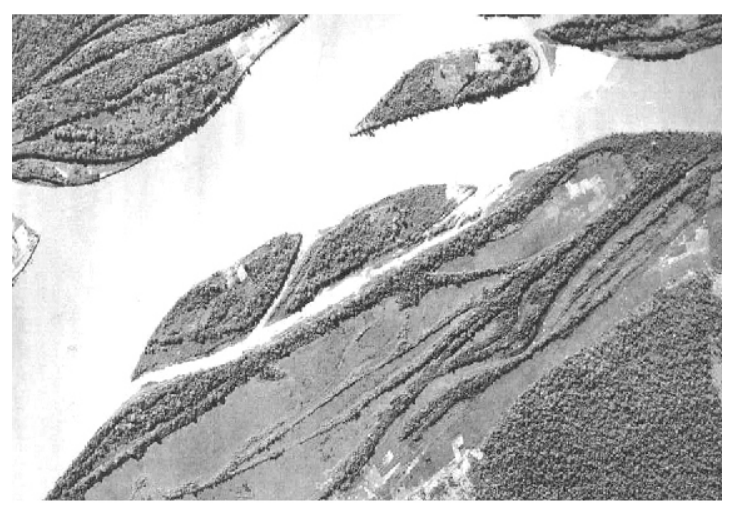

1970 obstrução por meio de barras de coalescência, que são ativas durante as cheias, mas se imobilizam em águas baixas e fecham os canais de entrada. Além dessas formas, ocorrem também barras laterais clássicas, que fazem o assoreamento nas partes a jusante das primeiras. A baixa velocidade de fluxo resultante da obstrução parcial do canal permite o intenso desenvolvimento do aguapé, o que intensifica o processo de abandono (Souza Filho \& Stevaux, 1997-a). A figura 2 apresenta os estágios da evolução deste canal desde a década de 1950.

\section{Metodologia}

A amostragem dos sedimentos de fundo e

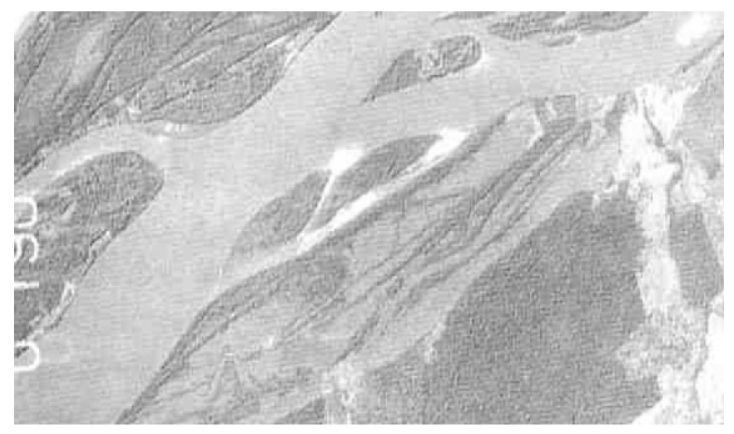

1965

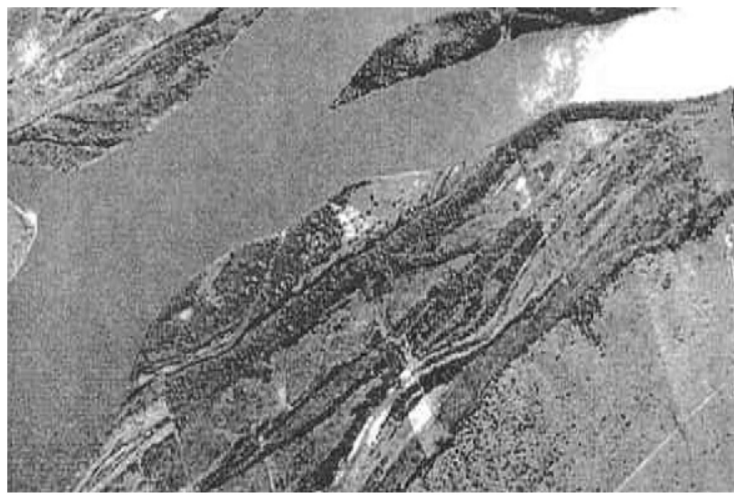

1996

Figura 2. Evolução morfológica do c anal Cortado - Rio Paraná (escala aprox. 1:60.000). Pode-se observar o importante papel das barras laterais de canal na evolução morfológica do canal Cortado. Em destaque na foto de 1953. (fotografias aéreas do acervo do GEMA-UEM).

dos dados hidrodinâmicos foi realizada no período entre abril de 1994 (vazante) e fevereiro de 1995 (cheia). Foram realizadas coletas de sedimentos do leito com pegador tipo van veen em uma seção transversal, onde foram amostrados três a quatro pontos de forma a caracterizar o talvegue e as porções laterais do canal (seção canal Cortado). Este tipo de pegador permite amostrar uma camada do leito de cerca de $10 \mathrm{~cm}$ de espessura, quando em sedimentos incoesos, como neste caso. Posteriormente, foi feita a análise granulométrica das amostras, através de peneiramento (escala Wenthworth - diâmetro em $\mathrm{mm}$ ). Na seqüência, foi feito o tratamento estatístico das amostras, através da aplicação da freqüência, desvio padrão, média, coeficiente de variação e correlação múltipla, com o auxílio dos softwares "Grânulo" "Statistica" e "Excel". Durante o período de coleta foram efetuadas medidas de velocidade de fluxo por meio de um 
fluviômetro, em cada ponto da seção, em séries verticais e a profundidades relativas de $20 \%$ da profundidade total. Foram feitas tomadas do nível da água a partir de réguas linimétricas instaladas no sistema (fig. 3). Os dados foram comparados com os valores obtidos por Stevaux et al. (1995) no rio
Paraná (seção Porto São José), no mesmo período, seguindo a mesma metodologia.

\section{Migração das Formas de Leito e do Talvegue no Alto Rio Paraná}

Variação das Cotas nos Canais da Planície do Rio Paraná

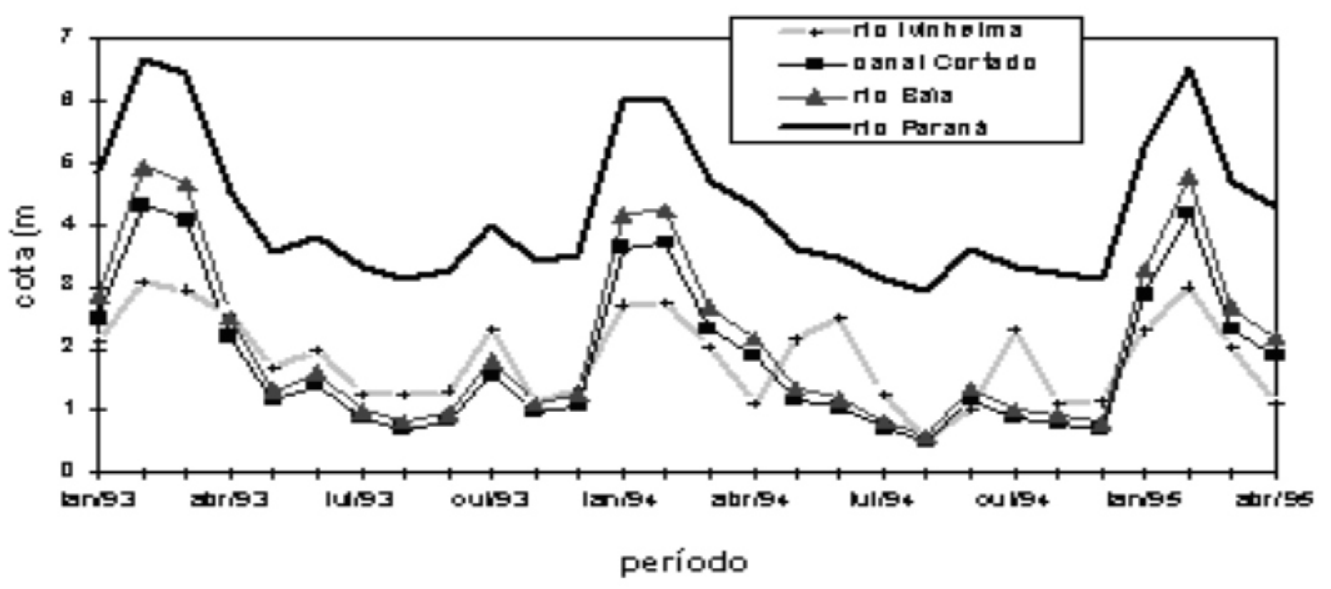

Figura 3. Hidrometria nos canais do sistema de inundação do rio Paraná. Fonte: Rocha \& Souza Filho (1996).

Neste sistema (fase de canal e fase de planície de inundação) coexistem os depósitos reliquiares de um provável sistema entrelaçado, constituídos por depósitos clásticos na base, já silicificados, cobertos por depósitos com características granulométricas mais finas (lama arenosa) de um padrão anastomosado anterior ao atual, encontrados nas ilhas e planície de inundação; e depósitos atuais, arenosos, encontrados no leito do canal, em barras e ilhas recentes. Em diversos trechos do canal do rio há intenso retrabalhamento dos depósitos de fundo, que se misturam a materiais mais recentes, provenientes das encostas, de afluentes e de montante.

$\mathrm{O}$ rio Paraná neste trecho (compartimento rio Baía) segundo Souza Filho (1993) exibe um padrão entrelaçado em planta, com a ocorrência de inúmeras barras arenosas e ilhas, que subdividem o fluxo em um sistema multicanal.

Segundo Santos (1997), os depósitos de canal do rio Paraná podem ser grosseiramente divididos em depósitos emersos de canal (barras e ilhas recentes) e depósitos no leito do rio (formas submersas). Souza Filho \& Stevaux (1997-b) classificaram os depósitos de canal como de lençol e de barras, subdividindo os primeiros em depósitos de lençol de canal profundo e de canal raso, os quais assumem grande importância para a interpretação e discussão a que se objetiva este trabalho:
Depósitos Emersos: as barras se diferenciam das ilhas por sua menor altura em relação ao nível do rio, menor estabilidade e por não apresentar vegetação arbórea. As ilhas, por sua vez, podem representar a evolução de barras por agradação. Neste caso, são formas geneticamente relacionadas ao canal fluvial atual. As barras fluviais são macroformas características no canal do rio Paraná, fundamentalmente arenosas e exibem dimensões que variam de centenas de metros até quilômetros, com histórias erosivas e deposicionais complexas (Santos, 1997).

Depósitos de lençol: são formas submersas extensas, cujas dimensões situam-se por volta de $1 \mathrm{~km}$ de comprimento, por $600 \mathrm{~m}$ de largura, em águas baixas. Sua espessura aumenta na direção do fluxo, até atingir um máximo na terminação a jusante. Eles ocorrem tanto em canais rasos quanto em profundos, diferenciando-se apenas quanto à espessura (Souza Filho \& Stevaux, 1997-b), com granulometria geralmente variando entre $1,0 \mathrm{e}$ 2,0 phi (areias médias a finas). Segundo estes autores, as principais formas são:

- $\quad$ Ondas de Areia (1 la ordem); são grandes formas de leito, atingindo até $6 \mathrm{~m}$ de altura e comprimentos superiores a $1 \mathrm{~km}$ em cheias com máximo perímetro úmido $(>7,4 \mathrm{~m}$ na régua da estação de Porto São José-PR, e recorrência de 
3,3 anos), com topo a $11 \mathrm{~m}$ de profundidade. São constituídas principalmente por areia fina a grossa com estratificação cruzada planar $(\mathrm{mSp})$. Estas formas se desenvolvem nas cheias, e conforme sua altura podem emergir quando em águas baixas, e sempre possuem sua parte superior composta por dunas sub-aquosas;

- Dunas Sub-Aquosas (2a ordem), variam entre 1,5 e 7,5 $\mathrm{m}$ de altura, e de 50 a $500 \mathrm{~m}$ de comprimento. Constituem formas de leito de Segunda ordem e são as mais típicas do rio Paraná. São constituídas por areia fina a grossa com estratificação cruzada festonada $(\mathrm{mSt})$ e por cascalho com estratificação cruzada acanalada (Gt). A ocorrência de cascalho nas dunas indica que provavelmente eles possam ocorrer nas ondas de areia, mas isso ainda não foi esclarecido. Desenvolvem-se em profundidades de 6 a $11 \mathrm{~m} \mathrm{e}$ sua parte superior é constituída de megaondulações;

- Mega-ondulações (3a ordem), sua altura varia entre 0,3 e 1,5 m, com até mais de $30 \mathrm{~m}$ de extensão, com forma linguóide ou luniforme. São feições de grande mobilidade e ocorrem em locais com mais de $3 \mathrm{~m}$ de profundidade, sendo constituídas de areia fina a média, com estratificação cruzada planar (Sp) quando em forma linguóide, e com estratificação cruzada festonada (St) quando em forma de meia lua. Em sua porção superior apresentam o desenvolvimento de ondulações;

- Ondulações, são formas de pequena amplitude, com até $0,3 \mathrm{~m}$ de altura máxima e alguns metros de extensão e ocorrem em águas rasas. Sua estabilidade é baixa, com migração rápida e freqüente troca de forma, embora comumente ocorra com formato linguóide. É constituída por areia fina, às vezes média, com estratificação cruzada planar $(\mathrm{pSp})$, ou festonada (pSt), ou ainda com marcas onduladas $(\mathrm{Sr})$.

Os depósitos em lençol de canal raso possuem menor amplitude que os anteriores, podendo chegar a $2 \mathrm{~m}$. Suas dimensões em planta são equivalentes às formas de águas profundas $\mathrm{e}$ são constituídos por ondas de areia extensas, dunas e ondulações. Sua constituição e altura são idênticas às das mega-ondulações linguóides $(\mathrm{Sp})$ e das luniformes ( $\mathrm{St}$ ), respectivamente. A diferença de extensão entre as formas de áreas rasas e de áreas profundas deve-se à superfícies disponíveis para seu desenvolvimento. A figura 4 ilustra as formas de leito observadas em 3 diferentes seções na região dos estudos. Nela pode-se observar a descrição da sobreposição de formas menores sobre as de maiores dimensões.

Do ponto de vista dinâmico, a movimentação das formas de leito e das classes granulométricas associadas é resultante dos fatores associados às condições hidrodinâmicas do fluxo que variam com o regime hidrológico do rio. Como o rio Paraná, neste trecho, apresenta dois períodos bem definidos de cheia (dezembro a março) e estiagem (abril a novembro), é esperada intensa modificação nas feições erosivas e deposicionais entre um período e outro (Santos, 1991; Stevaux, 1994; Fernandez \& Souza Filho, 1995; Rocha \& Souza Filho, 1996), podendo gerar grande aumento na capacidade do rio nos períodos de cheia (Fernandez et al., 2000) e consequentemente intensificação de processos erosivos nas áreas então erosivas, e de transporte, com grande mobilização e esculturação das formas de leito no canal..Em contra-partida, no período seguinte, maior intensificação nos processos da dinâmica deposicional, visto que há grande diminuição na competência do rio

A posição espacial dos setores energéticos é também controlada pela migração do talvegue. Esse comportamento migratório influencia a distribuição espacial das fácies de sedimentos de fundo, tendo em conta que o talvegue constitui o principal corredor de transporte de sedimentos de fundo e a deriva lateral do talvegue controla a distribuição espacial e temporal das áreas em erosão (remoção de barras e ilhas) e deposição (acreção de barras) (Fernandez et al., 2000). Stevaux (1994) mostrara que entre 1960 e 1990, a mudança na posição do talvegue em 3 diferentes seções transversais foi maior quanto maior o entrelaçamento da seção, sendo que no ponto nodal (canal único) foi de $2,7 \mathrm{~m} /$ ano e no trecho multicanal de $56 \mathrm{~m} /$ ano (Fig 5). Tais medidas mostram que existem grandes diferenças na velocidade de mobilização do talvegue ao longo do rio, provavelmente influenciada pela morfologia atual do rio, retrabalhando o sistema anastomosado pré-atual, - em fase de destruição (Rocha et al., 2001; Souza Filho et al., 2001; Santos et al., 2001) - que orienta a distribuição do fluxo e sua intensidade, e consequentemente nas formas de mobilização do leito, a despeito de uma provável trajetória rumo ao padrão entrelaçado (Souza Filho et al., 2001).

Essas características resumem um comportamento altamente dinâmico do leito dos canais principais do sistema entrelaçado. Porém, nos canais secundários rasos que cortam as ilhas, existe uma dinâmica diferente, visto que as condicionantes hidrológicas e de energia são bem menores, porém extremamente dependente dos canais principais, tanto em regime de vazante como, e principalmente, em regime de cheia.

\section{Relacionamento entre os Materiais do Leito do Canal Secundário (Seção Canal Cortado) e do Canal Principal (Seção Porto São José)}

\subsection{Granulometria dos sedimentos e geometria hidráulica}

Medidas de energia fluvial tem uma distribuição não linear para jusante, controlada pela descarga, raio hidráulico e declividade, sendo 

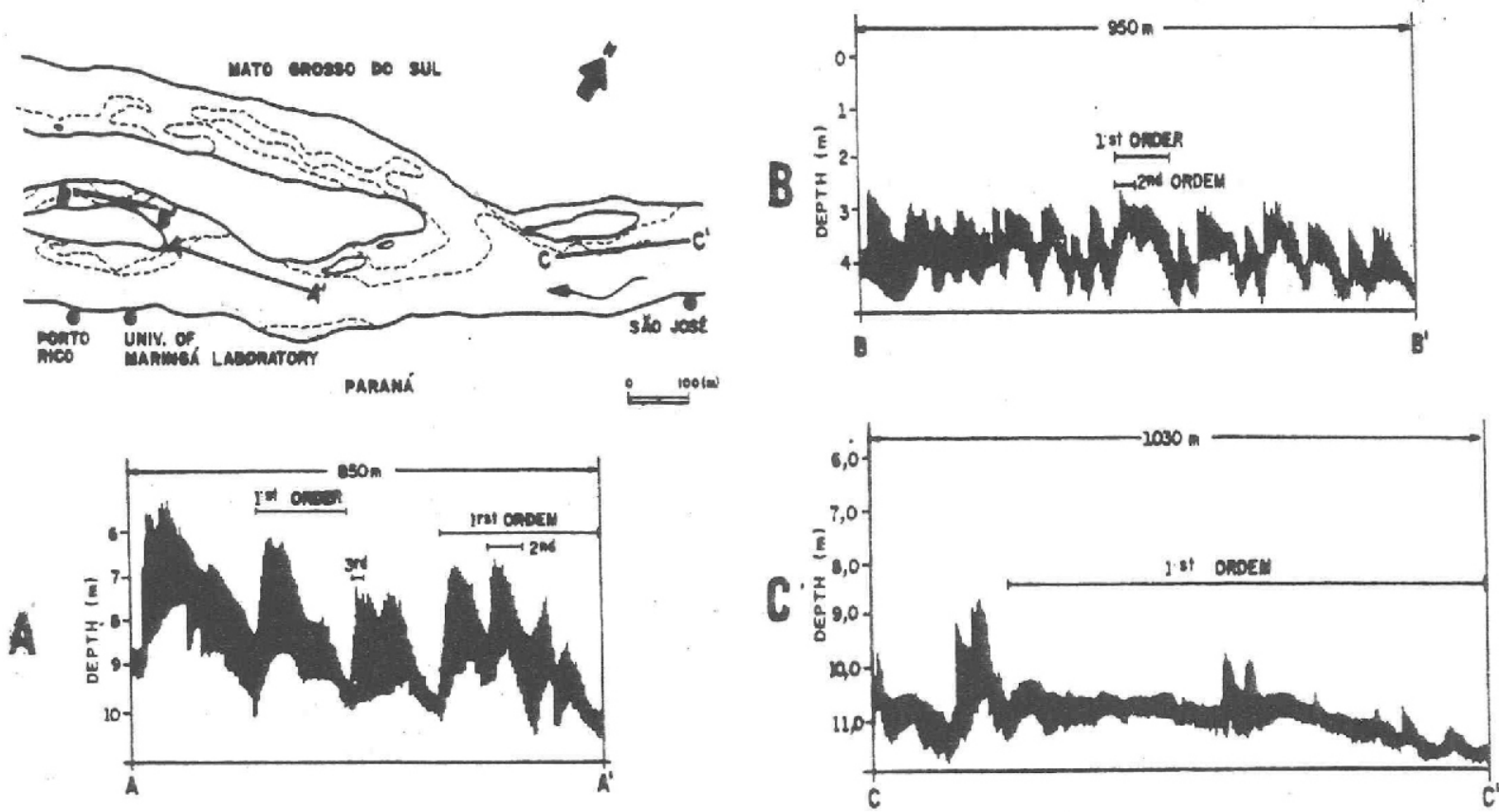

Figura 4. Ecogramas de três seções longitudinais no sistema entrelaçado do rio Paraná (conforme localização na parte superior da figura). Em $A$, perfil A A': meio de canal, com dunas ( $1^{\mathrm{a}}$ ordem), mega-ondas $\left(2^{\mathrm{a}}\right.$ ordem) ondulações ( $3^{\mathrm{a}}$ ordem); em $B$, perfil B B': canal secundário (canal Porto Rico), com mega-ondas ( $1^{\text {a }}$ ordem) e ondulações ( $2^{\mathrm{a}}$ ordem); em $C$, perfil C $\mathrm{C}^{\prime}$ : ponto nodal (canal único), com grandes megaondas e ondulações ( $1^{\mathrm{a}}$ ordem). Modificado de Stevaux (1994).
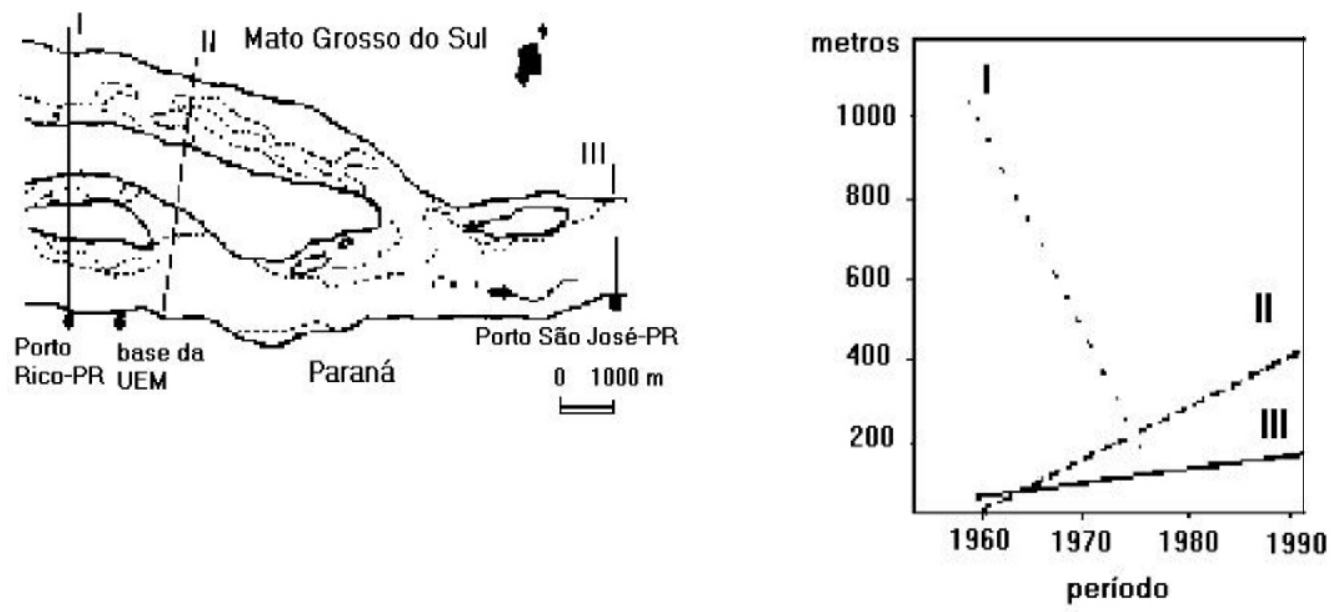

Figura 5. Migração do talvegue em três seções transversais no Alto Rio Paraná.: I trecho multicanal (ilha Porto Rico e a ilha Mutum); II canal duplo (montante da ilha Porto Rico); III ponto nodal (seção Porto São José). Modificado de Stevaux (1994). 
esta última mutante ao longo do canal, formando duas variantes no perfil de grandes rios. As maiores taxas de energia para o trabalho nos canais são observadas no trecho médio, com moderada descarga, moderado raio hidráulico e moderada declividade. Entretanto, para o transporte de sedimentos, a resistência dos grãos poderá também ser considerada (Petts \& Foster, 1990). As variações na energia podem se dar entre os trechos do rio e em sistemas multicanais, entre os canais, consequentemente resultando em variações no padrão de transporte de sedimentos entre um canal e outro, mesmo que temporariamente.

Os valores de velocidade média, nível da água, profundidade, raio hidráulico, relação largura/profundidade e nível do leito (relativo ao trabalho do rio: erosão ou deposição, que por sua vez se relaciona com o estágio do rio) estão apresentados na tabela 1, para o canal Cortado (canal secundário). O período de amostragem foi caracterizado por um evento de cheia inferior ao nível de margens plenas, portanto, sem transbordamento para a planície adjacente.

O aumento do raio hidráulico evidencia maior capacidade do canal em transportar materiais, porém não puderam ser avaliados os dados de variação na carga ao longo da tempo estudado. Da mesma forma, a relação largura/profundidade teve uma brusca ríodos de diminuição, indicando também para uma maior capacidade do canal. No entanto, foi observado que houve predominância de areias médias na seção. Além disso, as areias grossas foram mais freqüentes em períodos de menores energia, e as areias finas, por sua vez, nos períodos de maior energia.

Nota-se, também, que o nível do leito, por sua vez, não acompanhou a tendência das variáveis, mostrando elevação do fundo do canal durante o evento de cheia, indicando processo de deposição no leito (variável $\mathrm{T}$ da tabela 1), a despeito da maior competência denunciada, que na verdade, deve ser relativa à "passagem" de uma maior carga de sedimentos oriunda do canal principal do rio Paraná, discutidas a seguir.

A composição granulométrica em detalhe, dos sedimentos de fundo no talvegue da seção Porto São José (ponto nodal - rio Paraná) e do canal Cortado (trecho entrelaçado) encontramse nos gráficos da figura 6 .

No canal Cortado, houve um domínio de areia média ao longo de todo o ciclo; nos períodos de vazante (baixa velocidade) a areia grossa é a segunda fração mais freqüente, e nos períodos de cheia (maiores velocidades), a fração areia fina ocupa esta posição (fig. 6-A). Na seção Porto São José, da mesma forma, houve predomínio de areia média durante o ciclo. .

De modo geral, conforme as velocidades

Tabela 1. Variáveis hidráulicas e granulometria na seção canal Cortado (talvegue).

\begin{tabular}{|c|c|c|c|c|c|c|c|c|c|}
\hline $\begin{array}{l}\text { Variáveis } \\
\text { Período }\end{array}$ & $V m$ & $\mathbf{P}$ & $N a$ & $\boldsymbol{R h}$ & $L / P$ & $E$ ou $D$ & $\mathbf{A F}$ & $\mathbf{A M}$ & $\mathbf{A G}$ \\
\hline Abr/94 & 0.49 & 1.30 & 0.88 & 0.65 & 29.4 & & 14.8 & 52.4 & 24.0 \\
\hline Jun/94 & 0.49 & 1.20 & 0.77 & 0.60 & 30.1 & E 0.01 & 9.1 & 49.9 & 32.4 \\
\hline Ago/94 & 0.55 & 0.95 & 0.45 & 0.47 & 45.7 & E 0.07 & 16.1 & 53.3 & 25.1 \\
\hline Out/94 & 0.58 & 1.25 & 0.54 & 0.63 & 43.3 & Е 0.21 & 23.6 & 51.6 & 20.0 \\
\hline Dez/94 & 0.54 & 1.20 & 0.17 & 0.60 & 68.5 & E 0.40 & 13.8 & 58.1 & 25.0 \\
\hline$f e v / 95$ & 0.74 & 4.20 & 3.31 & 2.10 & 17.0 & D 0.14 & 29.0 & 64.4 & 5.2 \\
\hline abr (estim) & 0.49 & 1.30 & 0.88 & 0.65 & 29.4 & $D / E ?$ & 14.8 & 52.4 & 24.0 \\
\hline
\end{tabular}

$\boldsymbol{V} \boldsymbol{m}$ : velocidade média $(\mathrm{m} / \mathrm{s}) ; \boldsymbol{P}:$ profundidade $(\mathrm{m}) ; \boldsymbol{N a}$ : nível da água na régua linimétrica da seção; $\boldsymbol{R} \boldsymbol{h}$ : raio hidráulico; L/P: relação largura/profundidade; $\boldsymbol{T}$ : erosão $\underline{\mathrm{E}}$, ou deposição $\mathrm{D}$ na seção $(\mathrm{m}) . \boldsymbol{A F}$ : areia fina; $\boldsymbol{A M}$ : areia média; $\boldsymbol{A G}$ : areia grossa. 

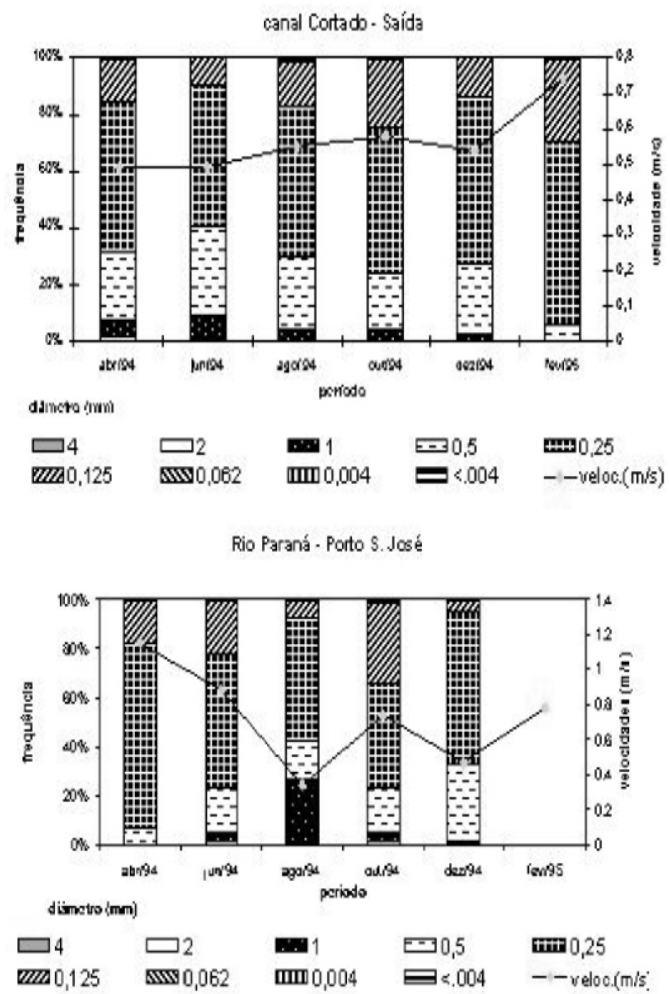

Figura 6. Velocidades e freqüências granulométricas no talvegue da seção canal Cortado (A) e Porto S. José (B)

diminuem, aumenta a presença das classes mais grosseiras. Nas duas seções, sob velocidades maiores, aumenta a presença das areias finas (fig. 6B).

A figura 7 mostra os valores relativos à média, desvio padrão e coeficiente de variação de todas as classes granulométricas identificadas e avaliadas ao longo do período estudado nas duas seções. Os valores mostram que no canal secundário (canal Cortado) há maior grau de seleção (fig. 7-A), provavelmente em função da menor variação da energia do fluxo, quando comparado com a seção de Porto São José (fig. 7-B). Nesta última, as grandes variações nas descargas ao longo do ciclo hidrodinâmico conduzem a alterações no padrão de transporte e nas formas de leito, correlatas também às variações da posição do talvegue.

A distribuição relativa das frações areia grossa e areia fina ao longo do ciclo hidrológico não coaduna com o comportamento da profundidade e da velocidade de fluxo nas duas seções. Pelo observado há diminuição da quantidade relativa de areia grossa e um aumento da areia fina justamente no período de aumento de velocidade e da profundidade. Tal situação já foi descrita no trabalho de Cunha (1993), no estudo do rio Capivari (rio de Janeiro).

Segundo a autora, as mudanças nos valores da vazão, ao longo do ciclo hidrodinâmico (vazante -

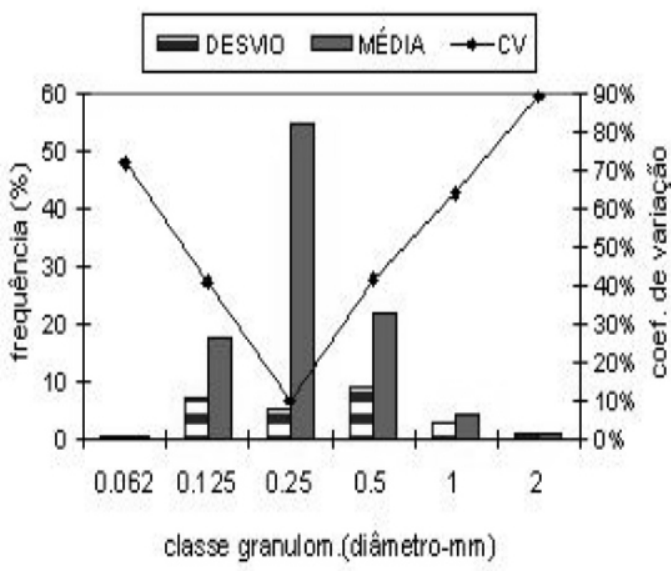

—DESVIO $\square$ MÉDIA $\rightarrow C . V$.

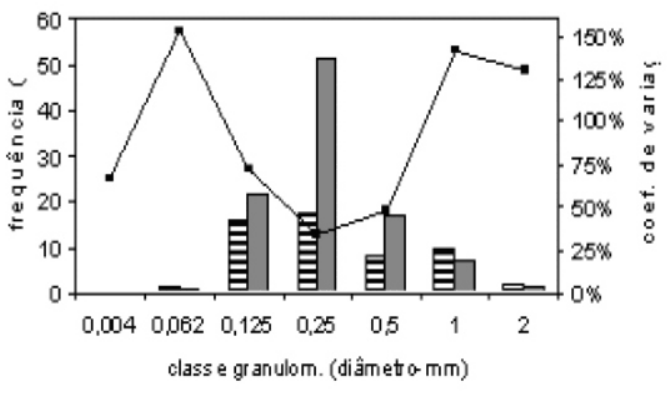

Figura 7- Parâmetros estatísticos relacionados aos dados de freqência granulométrica. A - seção canal Cortado; B - seção Porto São José.

cheia) para o período de 1987 - 1991 refletiram-se em acentuada variação na largura do canal e mudanças no calibre dos sedimentos predominantes, onde, durante a fase de cheia houve predominância de sedimentos mais finos no talvegue do canal, comparando-se com os valores iniciais, de vazante; ao final do ciclo, um menor selecionamento do material, com aumento do número de classes texturais e distribuição mais homogênea dos valores percentuais, denunciam alterações da energia do fluxo.

A correlação múltipla entre as variáveis no canal Cortado é ilustrada na figura 8 e mostrada na tabela 2. Observa-se que a correlação negativa entre a fração areia grossa e as variáveis velocidade, profundidade, raio hidráulico (correlatas aos padrões de energia na seção), indicam que tal fração não deve fazer parte da camada em transporte durante as amostragens, apesar de estar no raio amostral do pegador. No entanto, deve exercer um importante papel na composição das forças de resistência ao transporte, funcionando como substrato, e influenciando na movimentação das partículas sobrepostas. De qualquer modo, medidas diretas 
dos fatores de resistência ou rugosidade numa seção específica são pouco exploradas.

Observações diretas sobre o aumento na descarga e mudanças conjuntas nas outras variáveis tem indicado que a resistência do leito diminui com o aumento da descarga (Leopold et al., 1964).

Para materiais homogêneos no leito, o transporte da carga do leito geralmente reflete a variação de energia do rio, mas poucos rios

Correlações entre as Variáveis
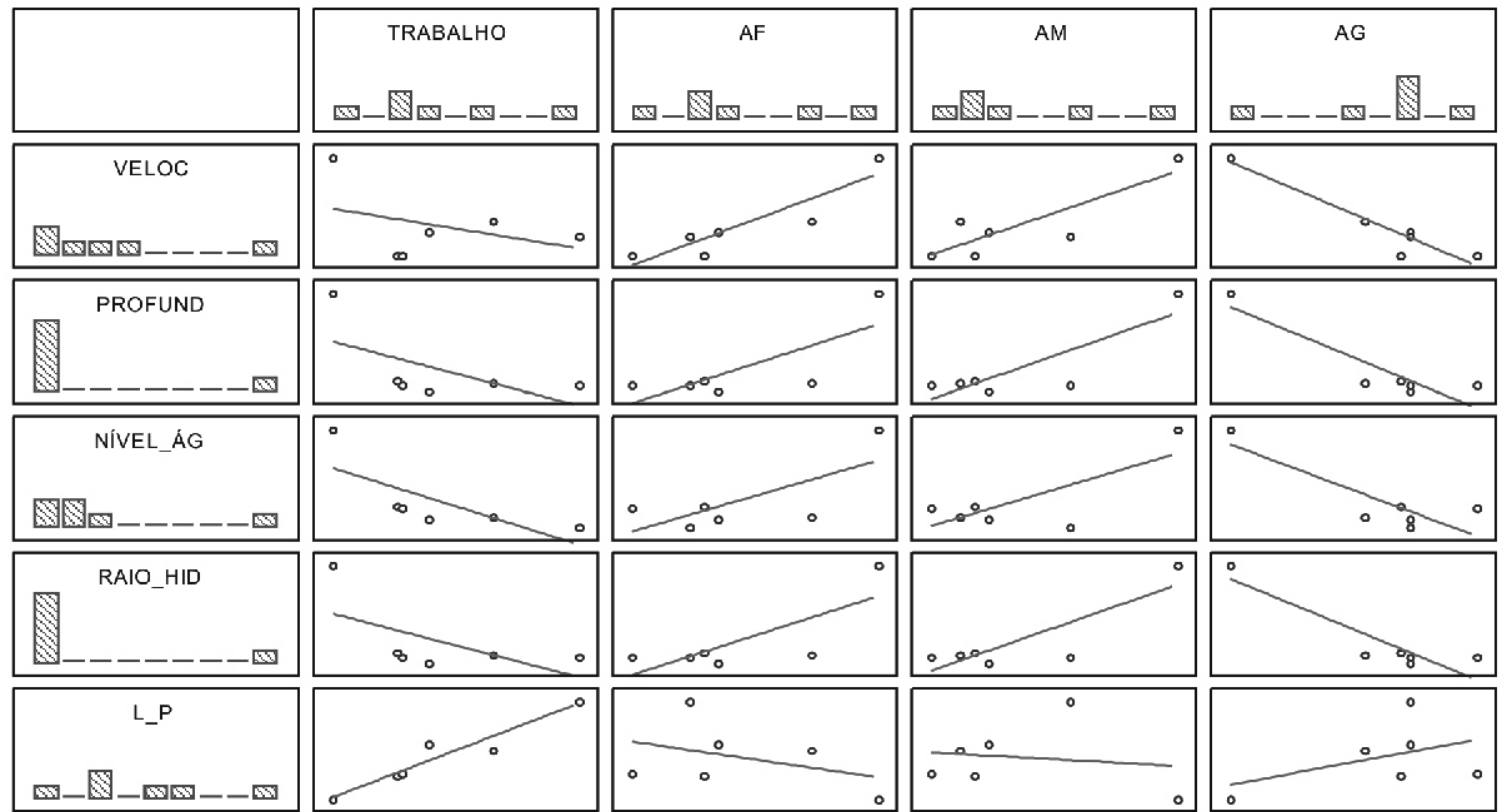

Figura 8- Correlacionamento entre as variáveis: ao alto estão as variáveis resposta (trabalho- erosão ou deposição;AF - areia fina; AM - areia média; AG - areia grossa); à esquerda estão as variáveis determinantes (Velocidade de fluxo; profundo; nível da água na régua da estação; raio hidráulico; L/P relação largura/profundidade).

Tabela 2. Índices de correlação múltipla entre as variáveis resposta e determinantes $(p<0,05)$.

\begin{tabular}{l|lllll}
\hline \multirow{2}{*}{ Variáveis respostas } & \multicolumn{4}{l}{ Variáveis determinantes } & \\
\cline { 2 - 6 } & Velocidade & Profundidade & Nível da água & $\begin{array}{l}\text { Raio } \\
\text { hidraúlico }\end{array}$ & $\begin{array}{l}\text { Relação } \\
\text { L/P }\end{array}$ \\
\hline Trabalho (E ou D) & $-0,38$ & $-0,59$ & $-0,74$ & $-0,59$ & 0,96 \\
Areias Finas & 0,91 & 0,76 & 0,72 & 0,76 & $-0,38$ \\
Areias médias & 0,85 & 0,85 & 0,75 & 0,85 & $-0,15$ \\
Areias grossas & $-0,95$ & $-0,90$ & $-0,85$ & $-0,90$ & 0,44 \\
\hline
\end{tabular}


naturais contém materiais homogêneos no leito, e então, uma variada interação entre fatores hidráulicos, sedimentológicos e bióticos complicam os processos de transporte de sedimentos. Em particular, quando partículas não transportáveis estão presentes no leito, o transporte seletivo dos sedimentos de menores tamanhos pode produzir uma camada de sedimentos grosseiros na superfície do leito, que protege os materiais subpostos da movimentação. Tal camada protetora pode exercer uma limitação na degradação do canal (Petts \& Foster, 1990). Isto evidencia interações mais complexas, envolvendo a carga sedimentar, o calibre dos materiais em transporte e as variáveis hidráulicas na seção transversal dos canais.

Tais fatos corroboram na interpretação do comportamento da relação entre o trabalho $^{1}$ no talvegue do canal cortado, apresentando relação direta com o índice L/P ( relação largura/profundidade), e inversa com as variáveis velocidade, profundidade, nível d'água e raio hidráulico (tab. 2), mostrando que as taxas de erosão acompanharam o aumento da relação $\mathrm{L} / \mathrm{P}$, e a diminuição nos valores de velocidade, profundidade, nível d'água e raio hidráulico (tab. 1).

Considerando as variações da geometria hidráulica (índices b, f e m de Leopold \& Madock, 1953, em Leopold et al., 1964) nas seções transversais dos canais ao longo do tempo, pode-se verificar que as maiores diferenças entre as duas seções foram observadas nos índices f (relação profundidade/descarga) e m (relação velocidade/descarga). No canal cortado, com o aumento da descarga, há maior aumento das profundidades (f), em relação à largura e à velocidade. Já no rio Paraná, na seção Porto São José, com o aumento dos débitos, há maior aumento na velocidade $(\mathrm{m})$, do que na profundidade e na largura respectivamente (Fig 9).

Tais fatos podem conduzir a um diferente comportamento no padrão de transporte de sedimentos, pela razão $\mathrm{m} / \mathrm{f}$ (taxa de aumento da velocidade com a descarga / taxa de aumento da profundidade com a descarga). Quanto maior for esta relação, mais rápido é o aumento da carga sedimentar com o aumento da descarga. Tal relação indica maiores valores para a seção do rio Paraná $(2,21)$, comparando-se com a seção do canal Cortado $(0,27)$.

Assumindo-se que a energia da declividade permanece constante nos períodos de erosão do leito e deposição sob a mesma descarga líguida, a resistência do fluxo pode ser menor quando a carga sedimentar em transporte for maior. Um aumento na velocidade e diminuição da profundidade (com declividade constante) está associada com um decréscimo na resistência do fluxo. Um aumento na carga em transporte está também associada com uma diminuição da resistência do fluxo. O canal reduz a resistência do fluxo pela modificação das formas de leito, as quais resultam em uma redução da profundidade.A variação na relação velocidade/profundidade sob uma dada vazão é então relacionada com a mudança na configuração do leito, que é incorporada como uma variável de causa e efeito neste relacionamento complexo. Tal configuração acompanha mudanças nos fatores hidráulicos e carga, e em parte, também, numa alteração na turbulência, as quais resultam em decréscimo na resistência do fluxo com o aumento da carga suspensa. A resistência do fluxo em um leito móvel depende um pouco do tamanho dos grãos, que exercem um efeito de superfície sobre a qual o fluxo trabalha. Este calibre do material pode auxiliar na natureza, ação e forma das feições construídas no leito, que exercem influência na resistência do fluxo (Leopold et al., 1964). Tais fatos podem explicar a passagem de uma maior carga sedimentar, de elementos finos e médios, através da migração de pequenas formas de leito durante os períodos de águas altas na seção canal Cortado.

Além disso, correlacionando-se os dados obtidos no sistema em estudo, as relações entre a profundidade e débitos com o material sedimentar em transporte parecem comandar tanto a configuração do leito quanto o calibre do material predominante na seção canal Cortado. No rio Paraná, seção Porto São José, as relações entre a velocidade de fluxo e os débitos com o material sedimentar fazem este papel.

\subsection{Relações Entre as Formas de Leito no Canal Cortado e nos Canais Principais do Rio Paraná}

No canal principal do rio Paraná, o período de cheia assume grande importância na esculturação das formas de leito, dada pela intensa movimentação dos materiais, principalmente sob forma de Mega-ondulações e dunas sub-aquosas nas áreas profundas e rasas (Souza Filho \& Stevaux, 1997-b). Segundo os referidos autores, as grandes cheias possuem papel ainda mais importante, pois permitem a movimentação de mega-dunas, dunas sub-aquosas de mega-ondas de areia, proporcionando uma rápida relocação do talvegue. As formas mencionadas inicialmente podem apresentar grande mobilidade, visto que Stevaux et al. (1995) chegaram a medir deslocamentos na ordem de $67 \mathrm{~m} / \mathrm{mês}$ durante um ciclo de cheia e vazante normais, como mencionado anteriormente. Como tais formas se movimentam com sobreposição de menores formas (com granulometria média de menor calibre) sobre as maiores (com granulometria média de maior calibre), é possível que as faixas granulométricas presentes nos períodos de baixas velocidades (areias médias e areias grossas) sejam das formas de maiores amplitudes e de menor mobilidade, ao passo que as faixas granulométricas presentes nos períodos de maiores velocidades (areias finas e areias médias) sejam das formas de menores amplitudes. 
Rio Paraná
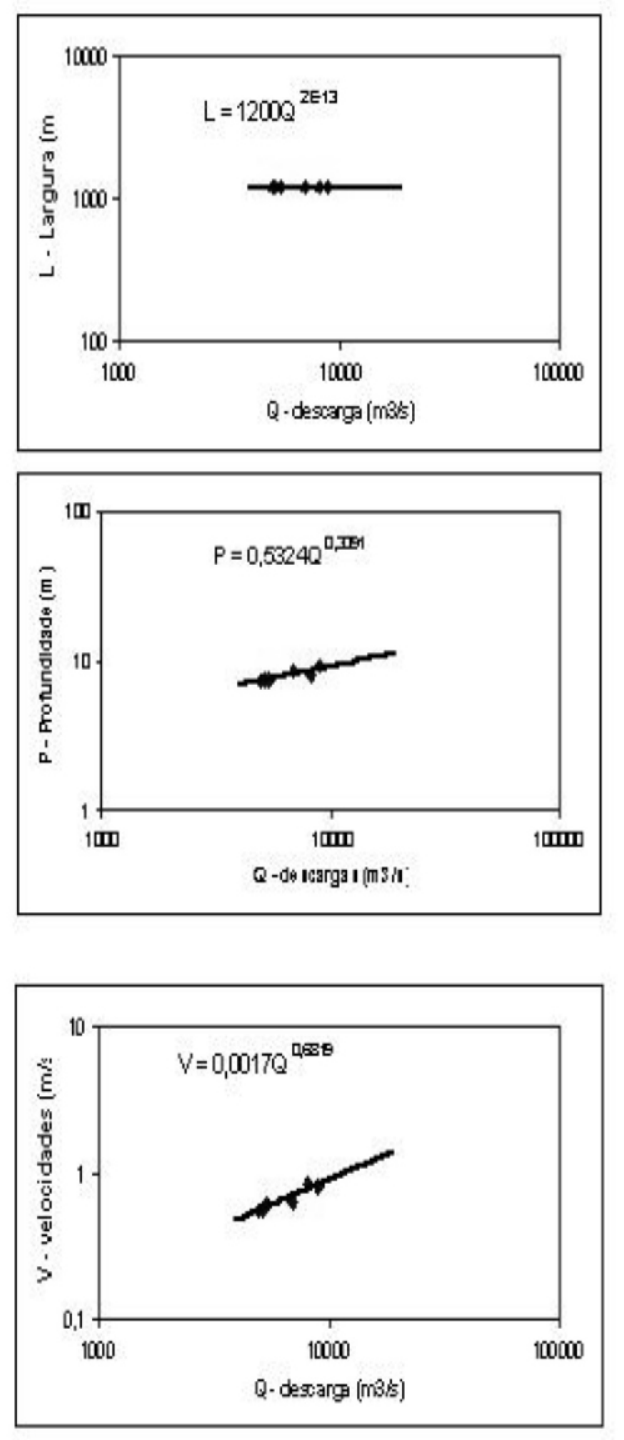

Canal Cortado
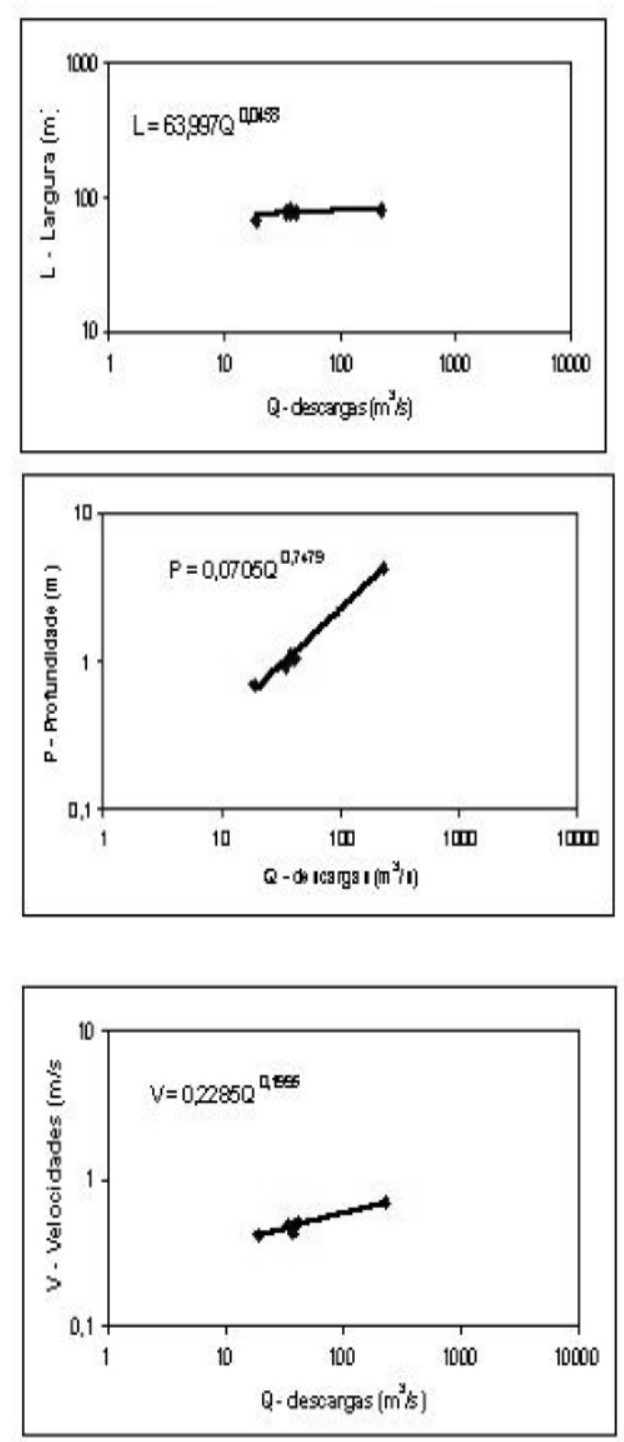

Figura 9. Relacionamento entre as descargas e as variáveis largura, profundidade e velocidade na seção Porto São José (rio Paraná canal único) e no canal Cortado (canal secundário do trecho multicanal) - İndices b, fe m da geometria hidráulica, em variação sazonal na seção transversal dos canais.

Do ponto de vista hidrodinâmico, em canais naturais pode-se resumir a três as principais variáveis responsáveis pela configuração do leito e os materiais em transporte - a profundidade do fluxo, a velocidade média do fluxo e o tamanho das partículas - apesar de outras variáveis estarem presentes, porém exercendo pouca influência (Harms et al.,1982). Considerando observações em laboratório, tais autores ressaltam que os relacionamentos de tamanho dos grãos $\mathrm{x}$ velocidades de fluxo para a faixa granulométrica entre 0,5 e 0,6 mm são mais complicados que para os sedimentos mais finos ou mais grosseiros. Nesta faixa granulométrica, com o incremento nas velocidades de fluxo, a sequência de formas são: sem movimento pequenas ondas leito plano inferior mega ondas leito plano superior anti- dunas. As interações entre velocidades de fluxo, tamanho dos grãos e formas de leito associadas, quando comparados os dados de campo das duas seções, mostram uma provável hierarquia do canal secundário (seção canal Cortado) para com o canal principal (seção Porto S. José). Usando-se tal relacionamento apenas para comparação entre as duas seções, pode-se verificar que para uma mesma faixa granulométrica nos dois canais, as formas de leito podem ser diferentes, acrescentando que, evidentemente no canal principal, os maiores valores de velocidades de fluxo são capazes de esculturar forma de maior porte (Fig 10), como já discutido em detalhe anteriormente.

Diante deste fato, é provável que o 
processo se desenvolva de maneira que a partir da entrada de partículas arenosas (areias médias e finas predominantemente) provenientes de formas de leito em migração no rio Paraná, o transporte dessas areias passa a ser comandado pelas condicionantes hidrodinâmicas locais, e influenciadas pela camada grosseira subposta, alterando assim as formas de leito inicialmente produzidas nos canais principais, passando de mega dunas e mega ondas para pequenas ondulações no canal secundário. A

\section{Canal Cortado}

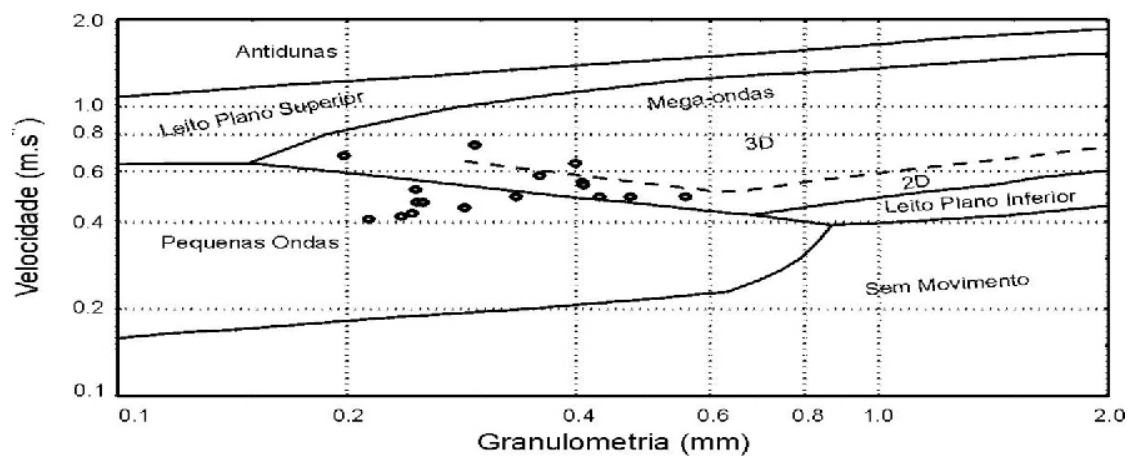

Rio Paraná

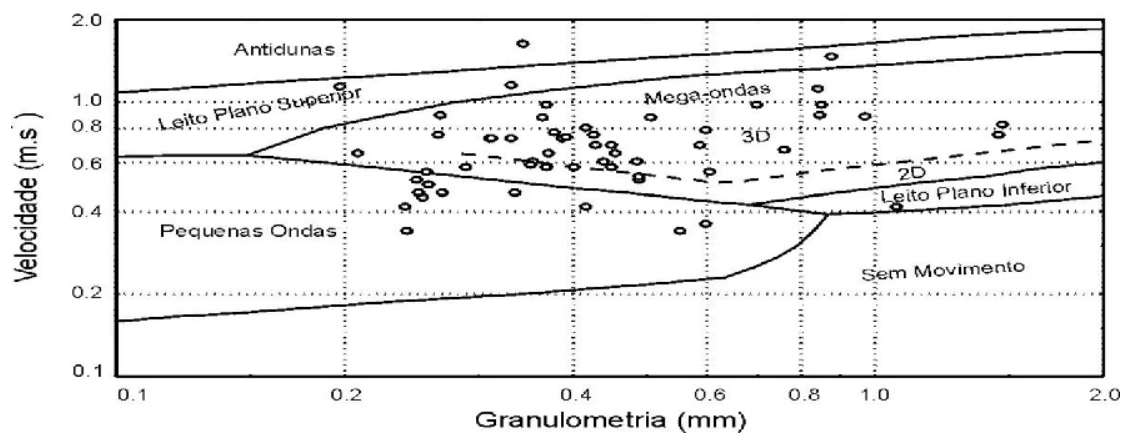

Figura 10 - Relacionamento entre as formas e leito dos grãos e velocidade de fluxo num canal principal do Rio paraná(A) e no canal Cortado (B). (Adaptado de Harms et al, 1982)

movimentação de tais areias já fora observada por Fernandez et al (2000), estudando seções transversais a jusante de Porto São José e comparando a ocorrência das classes granulométricas ao longo das seções e entre os canais principais esquerdo e direito.

Segundo tais autores, os sedimentos do braço direito do rio Paraná apresentam, em geral, um grau de seleção mais pobre e um amplo campo de distribuição. Por outro lado, os sedimentos do braço esquerdo, na maior parte, são moderadamente selecionados e o grau de seleção tende a aumentar com a diminuição do diâmetro médio. No caso do braço esquerdo do rio, onde se posiciona o canal Cortado, as areias são predominantemente mais finas (predomina areia média) que no braço direito (areia grossa) e apresentam valores de simetria negativos, indicando remoção seletiva. Além disso, os sedimentos do braço esquerdo apresentam curvas distributivas com maior tendência mesocúrtica e leptocúrtica entre os diâmetros 0,4 phi (areia grossa) e 3,2 phi (areia muito fina), indicando também possível remoção de materiais (transporte).

No caso do canal Cortado, os resultados mostram que o aumento da freqüência dos elementos mais finos ocorre junto com a elevação do fundo do canal (talvegue) durante a cheia; é possível então pressupor a passagem e transformação de formas de leito formadas a partir de sedimentos provenientes do canal principal do rio Paraná, com predominância de areias médias e areias finas, corroborando o que observou Fernandez et al. (2000). Tais formas sobrepõe-se aos sedimentos mais grosseiros do leito, previamente depositados, e, durante o período de abaixamento das águas os termos mais finos podem ser gradativamente removidos, levando à concentração dos grãos de maior diâmetro (Fig 11). Isso também mostra que há uma camada grosseira abaixo da zona de trabalho de leito deste canal, que deve ter sido depositada em um evento de muito alta magnitude, e que da mesma forma, só possa ser removida em tal 


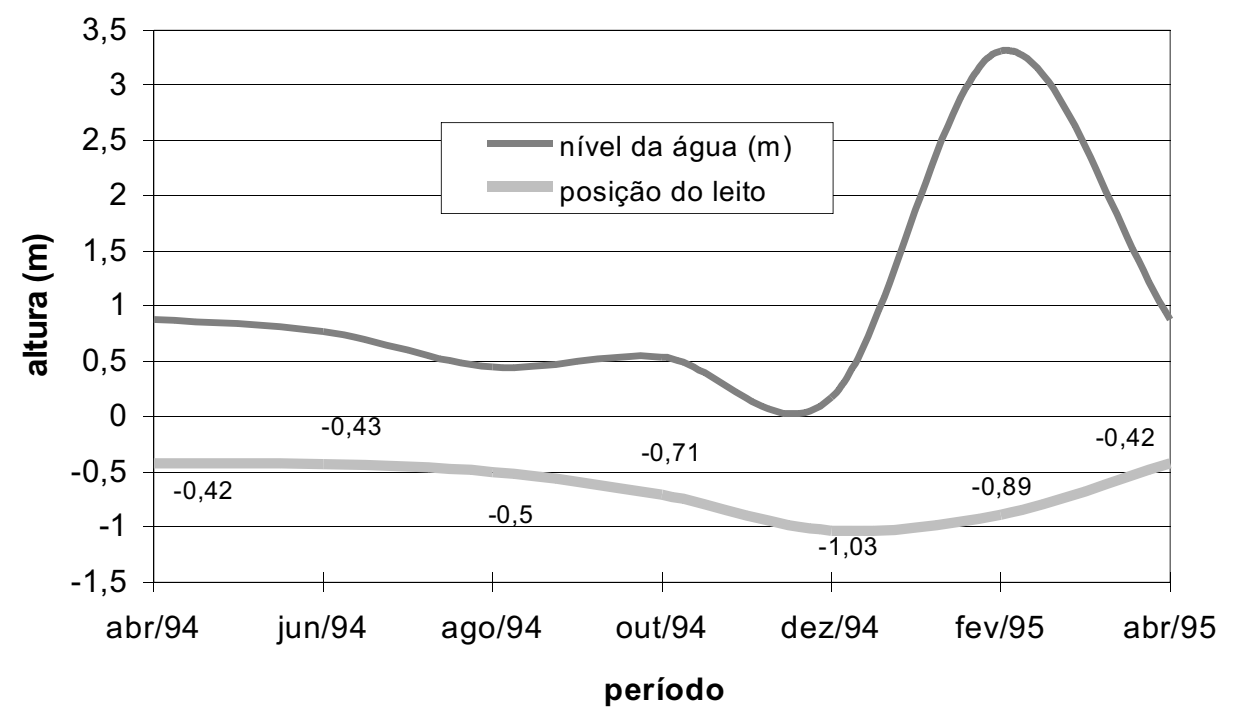

Figura 11. Variações dos níveis relativos do talvegue e da água na seção estudada. Obs: Abr/95 estimado.

evento, dependendo da inter-relação entre a energia do fluxo e a carga e calibre do material que chega com as correntes no canal Cortado, e estas por sua vez, condicionadas pelo direcionamento das principais linhas de fluxo dos canais principais do rio Paraná, a montante deste canal.

Apesar do grande aumento das profundidades no período de cheia no canal Cortado, as velocidades médias não aumentam na mesma proporção. A migração de pequenas ondulações parece ser predominante. Não há evidências de mega-ondulações neste canal mesmo em regime de cheia. É possível que o talvegue não tenha migrado de forma a direcionar os fortes fluxos de trabalho erosivo na direção do canal nas últimas cheias.

Presume-se assim, que as areias médias podem estar chegando no canal mas não estão sendo removidas na mesma proporção, tendo em vista sua homogeneidade na concentração ao longo do ciclo hidrodinâmico e sua melhor correlação com formas de leito maiores, inexistentes neste canal secundário.

A repetição anual de tais processos pode ser o mecanismo que leva ao assoreamento do canal, e é uma situação a ser considerada quando estudada a evolução dos canais secundários do rio Paraná. Este processo pode também explicar a origem dos termos grosseiros que constituem as mega-dunas sub-aquosas e as mega-ondas de areia do canal principal, além de sua baixa mobilidade.

\section{Conclusão}

Este estudo permite concluir que a interação entre a variação sazonal das condicionantes hidrodinâmicas e a entrada de material proveniente do rio Paraná na seção canal Cortado mostra-se insuficiente para o transporte contínuo de materiais entre as areias médias e areias grossas encontradas no seu leito (talvegue), permitindo a mobilização maior apenas das frações de areia fina. Tais variações sazonais são também responsáveis pelo desenvolvimento de processos de concentração de sedimentos grosseiros no seu leito.

Estes processos podem ser responsáveis pelo desenvolvimento de depósitos residuais e de formas de baixa mobilidade, que assumem forma de mega-dunas e de mega ondas de areia, no canal principal do rio Paraná. A movimentação dessas formas no canal secundário está na dependência de um fluxo extremamente forte (cheia de grande magnitude), onde possa haver erosão e transporte dos materiais de seu leito, e um novo ciclo se iniciar. Caso contrário, há uma gradativa deposição que pode levar ao abandono do canal.

As variáveis hidráulicas que comandam os processos de erosão (velocidades, raio hidráulico, profundidades) tiveram relacionamento inverso. No entanto, foi observado relacionamento direto com as freqüências das areias finas e areias médias. Isto pode estar relacionado ao fato de que junto com o aumento nos valores das variáveis hidráulicas, há um aumento na carga em transporte destas classes granulométricas em maior proporção, permitindo, assim a parcial deposição da carga e não a erosão do leito móvel desta seção durante a fase de águas altas. 


\section{Agradecimentos}

Os autores agradecem à $\mathrm{CAPES} / \mathrm{CNPq}$ pelo apoio financeiro; à UFMS e UEM pelo apoio logístico, em especial ao GEMA/DGE/UEM e seus funcionários pelo apoio técnico laboratorial; ao NUPELIA/UEM pelo apoio na aquisição dos dados de campo.

\section{Referências Bibliográficas}

Christofoletti, A. 1981. Geomorfologia Fluvial. Ed. Edgard Blücher. São Paulo-SP.

Chorley, R.J.; Schumm, S.A. \& Sugden, D.E., 1985. Geomorphology. Methuen, Inc., New York, $607 \mathrm{p}$.

Cunha, S.B. 1993. Impactos das obras de engenharia sobre o ambiente biofísico da bacia do rio São João (Rio de Janeiro-Brasil). Tese de doutoramento. Departamento de Geografia. Universidade Clássica de Lisboa, Lisboa, 415 p.

Fernandez, O.V.Q. \& Souza Filho, E.E. 1995. Efeitos do regime hidrológico sobre a evolução de um conjunto de ilhas no rio Paraná. Boletim Paranaense de Geociências, Ed da UFPR, Curitiba, ${ }^{\circ}$ 43:161-171.

Fernandez, O.V.Q., Santos, M.L., Fulfaro, V.J., 2000. Caracterização e distribuição dos sedimentos de fundo do rio Paraná em Porto Rico (PR). Ciência Geográfica, Bauru-SP, VI vol. I (15).

Harms, J.C., Southard, J.B. \& Walker, R.G., 1982. Structures and Sequences in clastic rocks. Lecture Notes for SEPM Short Course n. 9. Calgary.

Leopold, L.B., Wolman, M.G. \& Miller, J.P., 1964. Fluvial processes in geomorphology. Freedman, San Francisco, 319 p.

Petts, G.E. \& Foster, I., 1990. Rivers and Landscape. The Athenaeum Press. 2. Ed., New Castle. Great Britain.

Rocha, P.C. \& Souza Filho, E.E. 1996. Erosão Marginal em Canais Associados ao Rio Paraná, na Região de Porto Rico-PR. Boletim Paranaense de Geociências, N 44. Ed. UFPR. Curitiba-PR.

Rocha, P.C., Souza Filho, E.E. \& Fernandez, O.V.Q., 1999. Intensity of Erosive Processes at Channel Banks of the Upper Parana River, Porto Rico Town Area, Parana State (Brazil). International Symposium on Geomorphology and Paleohydrology of Large Rivers GLOCOPH. Goiânia-GO.

Rocha, P.C., Santos, M.L. \& Comunello, E., 2001. The Disequiliibrium Stage of Upper Parana River Flood System, Southern-Central Brazil. V REQUI/ I CQPLI, Lisboa, Portugal. Jul/2001. 137, 140 p.

Santos, M.L., 1991. Faciologia e evolução de Barras de Canal do Rio Paraná na Região de Porto Rico-PR. Rio Claro-SP. Dissert. de Mestrado.
Rico-PR. Rio Claro-SP. Dissert. de Mestrado. IGCE/UNESP. Inédito.

Santos, M.L., 1997. Estratigrafia e Evolução do Sistema Siliciclástico do Rio Paraná no seu Curso Superior: Ênfase à Arquitetura dos Depósitos, Variação Longitudinal das Fácies e Processos Sedimentares. Porto Alegre-RS. Tese de Doutorado. Inédito.

Santos, M.L. \& Stevaux, J.C. (2000) Facies and architectural analysis of channel sandy macroforms in the upper Parana river. Quaternary International, 72:87-94.

Santos, M.L., Rocha, P.C. \& Comunello, E., 2001. Sistema Fluvial do Rio Paraná (Brasil) em seu Curso Superior: Um Exemplo de Planície Aluvial em Desequilíbrio. V REQUI/ I CQPLI, Lisboa, Portugal. Jul/2001. Actis:145 148 p.

Souza Filho, E.E., 1993. Aspectos da Geologia e Estratigrafia dos Depósitos Sedimentares do Rio Paraná entre Porto Primavera (MS) e Guaíra (PR). Tese de Doutorado. Instituto de Geociências/USP. São Paulo-SP. Inédito.

Souza Filho, E.E. \& Stevaux, J.C. 1997a., Geologia e Geomorfologia do Complexo Rio Baía, Curutuba, Ivinheima. In: A Planície De Inundação Do Alto Rio Paraná. UEM-Nupelia.

Souza Filho, E.E. \& Stevaux, J.C. 1997b. As barras fluviais da parte média do alto rio Paraná. Anais do VI Congresso Brasileiro daABEQUA, Curitiba, v.1:265-269.

Souza Filho, E.E., Rocha, P.C., Correa, G.T. \& Comunello, E., 2001. O Ajuste Fluvial e a Erosão das Margens do Rio Paraná em Porto Rico (Brasil). V REQUI/ I CQPLI, Lisboa, Portugal. Jul/2001.37 40 p.

Stevaux, J.C., 1993. O Rio Paraná: Geomorfogênese, Sedimentação e Evolução Quaternária do seu Curso Superior (região de Porto Rico-PR). Tese de Doutorado. Instituto de Geociências/ USP. São Paulo-SP. Inédito.

Stevaux, J.C., 1994. Geomorfologia, Sedimentologia e Paleoclimatologia do Alto Curso do Rio Paraná (Porto Rico-PR). Boletim Paranaence de Geociências 42. Curitiba-PR.

Stevaux, J.C.; Takeda, A.M.; \& Moraes, M. 1995. Dinâmica sedimentar no canal do rio Paraná. Simpósio Sul Brasileiro de Geologia / $1^{\circ}$ encontro de Geologia do Cone Sul. SBG, Porto Alegre, Anais, v. 1: $284-286$. 